\title{
Ist Santonsäure wirklich ein ausschliessliches Hirnkrampfigift?
}

\author{
Von
}

\section{B. Luchsinger.}

Entgegen der auch jetzt noch immer wieder angebeteten Lehre spezifischer Hirnkrampfgifte habe ich zu wiederholten Malen eine principielle Einheit im Verbalten aller motorischen Ganglien des gesammten Centralnervensystems irgend welchen reizenden Giften gegenïber eifrig betont. Ich hatte für einige Typen dieser Lehre, für Pikrotoxin, Campher, Cocain eben auch am isolirten, von dem übrigen Centralnervensystem durch einen Schnitt unter der medulla oblongata abgetrennten Rückenmarke recht dentliche Erregungen wahrgenommen, die sich an den verschiedensten peripheren Organen, an den Sceletmuskeln, an den Gefässmuskeln, an den Schweissdrüsen geltend machten.

Wenn dadurch nunmehr die Frage der sog. Hirnkrampfgifte im Principe zu deren Ungunsten entschieden sein dürfte, so werde ich künftig gleichwohl, so wie mir aus anderweitigen Gründen passend hergerichtete Rückenmarke zur Verfügung stehen, auch andere bisher als solche Hirnkrampfgifte noch geltenden Substanzen dem Versuche unterwerfen. Je mannigfachere von jenen Substanzen dann eben positive Wirkungen selbst am blossen Rückenmarke bekunden, um so eher wird endlich allgemein jene a priori schon so unwahrscheinliche, aber doch so unglaublich zäh festgehaltene Lehre fallen.

Binz') hat vor mehreren Jahren in der Santonsäure ein Agens angegeben, das heftige Krämpfe erregt; es sollen diese Krämpfe aber verschwinden, sowie das Rückenmark von dem verlängerten getrennt wurde.

So soll die Santonsäure eben ausschliesslich die Krampfcentren des Mittelhirns and des verlängerten Markes erregen.

1) Binz, Archiv für experimentelle Pathologie und Pharmakologie Bd. VI, p. 303, 1877. 
Ich habe bei einigen Kaninchen, denen zu andern Zwecken Hirn und verlängertes Mark durch Ligatur der vier Halsarterien abgetödtet waren, deren Allgemeintod aber Dank künstlicher Respiration noch hinausgeschoben wurde, Lösungen von santonsaurem Natron in die Jugularvene langsam injicirt.

Nach wenig Minuten erschienen am Hinterthier, am Schwanz zuerst, dann aber auch recht kräftig an den Hinterbeinen krampfartige Bewegungen. $\mathrm{Zu}$ solcher Zeit wurde mit der nöthigen Vorsicht der Thorax geöffnet, das Herz schlug noch recht kräftig, selbst kleine, absichtlich angeschnittene Arterien bluteten gut, es waren also die beobachteten Krämpfe des Hinterthieres nicht etwa bloss als dyspnoische zu deuten, von Herzschwäche abzuleiten, diese Krämpfe sind eben vielmehr Zeichen einer directen Erregung des Riïckenmarkes durch die Santonsäure.

Dass allerdings bei kleinsten Dosen das-gesammte Centralnervensystem leichter Erregungen entwickeln wird, als das isolirte Rückenmark, habe ich schon zu wiederholten Malen in diesem Archive erörtert.

\section{Zur Innervation der Iris des Kaninchens.}

$$
\text { Von }
$$

\section{B. Luchsinger.}

Stellt man ein Kaninchen, am besten ein albinotisches, so gegen das Licht, dass das eine Auge gat beleuchtet, das andere aber beschattet ist, so sieht man eine erhebliche Differenz in der Weite der beiden Pupillen.

Immer wird der Sphincter des beleuchteten Auges viel stärker contrahirt sein als wie jener des beschatteten.

Anders ist es bekanntlich beim Menschen. Denn hier sind auch trotz verschiedener Belenchtung beider Augen normal die Pupillen doch stets gleich weit. 